\title{
Editorial
}

\section{Un futuro sostenible}

\author{
José Félix Hoyo Jiménez
}

Presidente de Médicos del Mundo España y Director del Master Universitario en Acción Humanitaria Sanitaria; josefelix.hoyo@medicosdelmundo.org; ORCID id: https://orcid.org/0000-0003-3901-5421

DOI: https://doi.org/10.37536/RIECS.2020.5.S1.186

Los objetivos de desarrollo sostenible (ODS) fueron aprobados el 25 de septiembre de 2015. Ese día, 193 países, incluido el nuestro, nos comprometimos con los 17 objetivos y su cumplimiento para el año 2030. Los ODS persiguen la igualdad global y proteger y asegurar la prosperidad como parte de una nueva agenda de desarrollo. Pero, sobre todo, los objetivos pretenden, como su propio nombre indica, conseguir la sostenibilidad global del planeta. "La sostenibilidad consiste en satisfacer las necesidades de la actual generación sin sacrificar la capacidad de futuras generaciones de satisfacer sus propias necesidades" (Brundtland, 1987). Para lograr estos objetivos se han tenido muy en cuenta las interrelaciones existentes entre las diferentes áreas que intentan garantizar esa sostenibilidad. La conclusión general nos dice que es imposible lograr el fin sin la premisa de "NO dejar a nadie atrás".

Los conflictos y las catástrofes naturales han convivido con el ser humano desde siempre. Los primeros, cíclicamente como períodos glaciales, con mayor o menor extensión e intensidad, evitables, parece que "ineludibles" se han propagado en los últimos años hasta cifras de personas afectadas que no se veían desde la Segunda Guerra Mundial. Muchos de ellos olvidados o desatendidos producen los mayores niveles de desigualdad sobre la tierra, convirtiendo a las personas sobre las que repercuten en extremadamente vulnerables y destruyendo todos los sistemas de protección social. La salud se resiente con un aumento significativo de la morbilidad y mortalidad global por diversos factores que no son solo derivados directamente de la violencia. La desestructuración del sistema sanitario produce más muertes que las armas, y las armas utilizan también a la Salud para ganar las guerras. Durante los períodos de conflicto se reavivan enfermedades supuestamente casi erradicadas o insignificantes cuando se cumplen los calendarios de vacunación habitual. Los conflictos, las guerras dejan a millones de personas atrás.

Durante todo este siglo y de forma cada vez más acelerada, el cambio climático produce un aumento de los desastres naturales. Las inundaciones y sequias y sus consecuencias, los incendios, la calidad y cantidad del agua, las temperaturas extremas ponen, en jaque a los sistemas sanitarios exigiendo medidas de preparación, contención, reducción de riesgo y mitigación, que comprometen los fondos destinados a la atención sanitaria. Se están produciendo cambios acelerados en los ecosistemas que desequilibran o amplían el hábitat de reservorios y vectores, los que aumenta considerablemente el riesgo epidémico con zonas afectadas por enfermedades antes consideradas "tropicales". El riesgo de desastre es significativamente mayor para las personas vulnerables y se nutre y produce un grave aumento de las desigualdades. Las consecuencias de esta realidad producen, de hecho, desplazamientos humanos masivos, de nuevo conflictos, inseguridad alimentaria y brotes epidémicos.

El mundo está cada vez más relacionado y la realidad del planeta es solo una. No olvidemos que, por ejemplo, los terribles incendios que están sucediendo en un lugar tan lejano como Australia aumentan el $\mathrm{CO}_{2}$ que se vierte a la atmosfera y acaban con el tampón natural del mismo que son los bosques destruidos. No son solo una noticia en los periódicos, sino que son causa y consecuencia del calentamiento global que amenaza nuestras costas. Lo que parece claro, con cada vez mayor evidencia científica, es que el tiempo para la acción es ahora, cuando todavía queda tiempo.

Otra de las características de la agenda 2030 es la llamada a la responsabilidad individual y social. Parece claro que la consecución de los ODS tiene un elemento clave en la responsabilidad política. Pero la sociedad civil debe reclamar y participar en esa responsabilidad y no olvidar que, 
cada persona, también es responsable de los avances o retrocesos que se vayan produciendo. Debemos ser capaces tomar las riendas de nuestro propio destino.

Las consecuencias de todos los procesos descritos previamente, la complejidad del entorno, la responsabilidad particular y social precisa de diversos elementos que permitan crear las capacidades para afrontar la nueva realidad. Desde una organización no gubernamental centrada en salud como Médicos del Mundo cuyo papel es conseguir que el Derecho a la Salud sea una realidad para todas las personas del mundo, especialmente las más vulnerables, es una obligación adaptarnos a este entorno. Para ello, necesitamos mejorar todos nuestros procesos de trabajo y contar con profesionales más y mejor formados que nos permitan realizar está difícil y, por desgracia cada vez más necesaria tarea de curar, dar testimonio y, en su caso, denunciar.

Millones de personas, cada vez más, necesitan que nuestra labor sea realizada con la más alta calidad posible. La alianza con la Universidad de Alcalá ha permitido crear y sostener el Máster de Acción Humanitaria Sanitaria (MUAHS). La Acción Humanitaria responsable es un elemento clave para que nadie se quede atrás. En muchos lugares del mundo las personas comprometidas en estos proyectos son las únicas que pueden acceder a todas esas personas vulnerables. Pero no se trata estrictamente de paliar el sufrimiento o la carencia de atención, no se trata de caridad, sino más bien de crear los cimientos para que esa acción sea sostenible. Para ello, es necesario un enorme respaldo de conocimientos teórico-prácticos que nos permitan hacer nuestra función cada vez mejor.

Sirva esta alianza como un ejemplo más del compromiso con el futuro sostenible de ambas instituciones.

(C) 2020 por los autores; Esta obra está sujeta a la licencia de Reconocimiento 4.0

Internacional de Creative Commons. Para ver una copia de esta licencia, visite http://creativecommons.org/licenses/by-nc-nd/4.0/. 